\title{
Aproximaciones filosófico-políticas sobre las nociones de indio, inca y mestizo en los Comentarios reales de los Incas ${ }^{1}$ \\ Political-Philosophical Perspectives about the Notions of Indian, Inca, and Mestizo on the Comentarios reales de los Incas
}

\author{
Alejandro Javier Viveros Espinosa \\ Universidad de Chile \\ CHILE \\ aviveros@u.uchile.cl \\ [Hipogrifo, (issn: 2328-1308), 4.2, 2016, pp. 363-373] \\ Recibido: 13-01-2016/ Aceptado: 23-02-2016 \\ DOI: http://dx.doi.org/10.13035/H.2016.04.02.24
}

Resumen. Este escrito posiciona algunas aproximaciones filosófico-políticas en torno a la Primera parte de los Comentarios reales de los Incas (1609) del Inca Garcilaso de la Vega. Para ello se despliegan dos movimientos hermenéuticos. El primero refiere a un cuestionamiento teórico-metodológico relativo a la noción de indio como construcción discursiva en los Andes coloniales. El segundo conduce un ejercicio crítico basado en la interacción entre las nociones de indio, inca y mestizo, que se focaliza en cómo éstas construyen subjetividades alternativas. Ambos movimientos consolidan una lectura sobre las reflexiones filosófico-políticas del Inca Garcilaso destacando sus propuestas respecto de un proyecto civilizatorio moderno bifurcado en el Nuevo Mundo.

Palabras clave. Filosofía política, indio, inca, mestizo, Inca Garcilaso de la Vega.

Abstract. This essay posits certain political-philosophical perspectives on the Inca Garcilaso de la Vega's Primera parte de los Comentarios reales de los Incas (1609). To this purpose we will develop two hermeneutical movements. The first re-

1. Resultado del proyecto CONICYT/FONDECYT Postdoctorado N 3140318 «Construcciones identitarias y traducciones culturales. Reflexiones filosófico-políticas sobre la noción de indio en Mesoamérica y los Andes coloniales (1570-1640)». 
fers to a theoretical and methodological questioning related to the notion of Indian as a discursive construction during colonial times in the Andes area. The second deploys a critical exercise grounded on the interaction between the notions of Indian, Inca, and Mestizo, which is focused on how they build alternative subjectivities. Both movements consolidate an interpretation about the Inca Garcilaso's political-philosophical reflections, remarking his proposals of a bifurcated modern civilizational project in the New World.

Keywords. Political Philosophy, Indian, Inca, Mestizo, Inca Garcilaso de la Vega.

Este escrito tiene por objetivo distinguir y proponer elementos útiles para una aproximación e interpretación filosófico-política ${ }^{2}$ referida al pensamiento del Inca Garcilaso de la Vega (1539-1616), particularmente en su problematización - presente en su célebre «Primera parte de los Comentarios reales de los Incas» (1609)respecto de las nociones ${ }^{3}$ de indio, inca y mestizo. A fin de reconocer la profundidad del pensamiento del Inca Garcilaso, intentaremos recuperar un acercamiento inquisitivo a través de movimientos concéntricos que, en diferentes perspectivas, permiten dilucidar el objeto de investigación ${ }^{4}$. Siguiendo estas indicaciones, que nos alejan de un camino progresivo (teleológico) y nos conducen por senderos alternativos y fragmentarios, desarrollaremos dos movimientos interrelacionados. El primer movimiento posiciona algunos elementos teóricos y conceptuales que nos permitan reconocer a la noción de indio en los Andes coloniales como un problema filosófico-político abierto y en directa relación con procesos de construcción identitaria y cultural. Consecuentemente, el segundo movimiento incorpora una lectura propositiva sobre los Comentarios, desde la cual sea posible reconocer algunos elementos centrales sobre las nociones de indio, inca y mestizo.

\section{ALGUNAS ACLARACIONES EN TORNO A LA NOCIÓN DE INDIO EN LOS ANDES COLONIALES}

Nuestro objetivo es distinguir algunas aproximaciones filosófico-políticas en el pensamiento del Inca Garcilaso a través de tres conceptos complejos y difíciles,

\footnotetext{
2. Brevemente, la filosofía política -en términos generales - refiere a un cuestionamiento por la vida en comunidad, las formas de gobierno, la justicia, los derechos y la libertad. La filosofía política es parte de un cuestionamiento por el ser humano en la pólis, es decir, como «ser social» o «animal político» (Aristóteles, La política, pp. 50-51) y, ciertamente, por su capacidad de articular diferentes modos de vida y convivencia, constituyentes de diversas costumbres, culturas e identidades.

3. El término noción tiene como raíz el vocablo latino notio, el cual es una traducción de las palabras griegas énnoai (idea en general) y prólepsis (idea o imagen anticipada). El término noción es atribuido a Cicerón, quien la usa como sinónimo de pensamiento, idea, imagen en el espíritu o designio. Entendemos al término noción destacando que: «En el sentido de "pensamiento", "idea", "concepto", "representación" y otros vocablos análogos, el término noción ha sido, y sigue siendo empleado de modo muy general; se llama noción a la idea o concepto de algo, y más específicamente a una idea o concepto suficientemente básico» (Ferrater Mora, 1994, p. 290).

4. Acevedo, 2003, pp. 18-19
} 
a saber, las nociones de indio, inca y mestizo. Bajo este objetivo central hemos decidido proseguir propedéuticamente con la noción de indio y, ciertamente, con su construcción colonial andina. Los caminos para cuestionar las construcciones discursivas elaboradas sobre la noción de indio son múltiples. Destacamos el esquema que propone José Luis Martínez, especialmente porque aclara los modos de descripción e interpretación que fueron utilizados en el contexto histórico-cultural colonial latinoamericano. Los clásicos estereotipos del «salvaje, bestia, bárbaro, infiel, pagano, oliváceo, etíope y similitudine homines» funcionan como vehículos interpretativos de la naturaleza del indio, de su capacidad intelectiva y sus costumbres, y se explican dentro de un proceso de homogeneización de la alteridad (heterogeneidad) de los seres humanos en el imaginario clasificatorio europeo del siglo $\left.X \mathrm{~V}\right|^{5}$. Recordemos que la clasificación de seres humanos es un ejercicio de poder que configura discursivamente nuevos sujetos o subjetividades, en este caso, a través de la noción de indio. Bien sabemos que esta noción llega a los Andes como una subjetividad ya creada 6 . En ella se distinguen algunos «momentos» de construcción discursiva sobre los indios donde se reconocen dos tipos de discursividades concordantes con dos paradigmas culturales, uno devenido de la «semejanza» y otro de la «diferencia», y que posicionan el «gran modelo intelectual epistémico de Occidente» ${ }^{7}$. Es decir, posicionan un conjunto de maneras de referir y construir una estructura de significación fundamental donde se distingue y se jerarquiza un nosotros y un otro (alteridad). En este punto es posible incorporar el concepto de «etnificación» porque profundiza en los modos de clasificación de lo indio. Sobre ello, y desde una comprensión teórica, sostiene Martínez:

Si, por un lado, estos procedimientos son interesantes para entender ciertos mecanismos de semantización y etnificación, no se puede dejar de lado otro aspecto: el que cualquiera sean las discursividades a las que se acuda, todas ellas utilizaron las mismas prácticas culturales de los otros (un conjunto de signos relativamente reducido) para etnificarlos. El etnocentrismo implica imponer, de todas maneras, sus propias marcas significantes (visuales, auditivos, olfativos) y abarcar cualquier práctica cultural: instituciones sociales, prácticas políticas o sociales, uso de objetos y emblemas, etc. La significación está dada por una operación simple: es la sociedad que etnifica quien toma significante cualquiera de esas prácticas y lo hace a través de una operación de presencia-ausencia.

La performatividad de todos estos discursos y sus varias discursividades, es evidente: a lo largo del siglo XVI se construyó, efectiva y eficazmente, ese nuevo sujeto social y cultural: el indio, con un rasgo esencial: que bajo condiciones de coacción o de asimilación, de desestructuración o de readecuaciones, fueron muchas las sociedades indígenas que aceptaron esa nueva condición y la incorporaron a un nuevo proceso de construcciones identitarias, así como otras siguieron manejando sus antiguas denominaciones ${ }^{8}$.

5. Martínez, 2007, pp. 25-26.

6. Es necesario reconocer en el espacio caribeño y mesoamericano instancias anteriores y experimentales. Ambos espacios presentan antecedentes fundamentales para la construcción y la comprensión de la noción de indio en los Andes coloniales. Ver Bernand y Gruzinski, 1996.

7. Martínez, 2007, pp. 31-32.

8. Martínez, 2007, p. 34. 
Siguiendo lo señalado, los derroteros del etnocentrismo abren lugar para la articulación de procesos de etnificación y construcción discursiva llevados a cabo sobre y desde las otras subjetividades en el Nuevo Mundo. En este contexto, son las prácticas culturales (y su performatividad) aquello que permite reflexionar sobre nuevos horizontes de pregunta en los cuales la semejanza y la diferencia operan tensionadas a través de un nuevo sujeto social y cultural. En este contexto, es posible integrar algunas propuestas de carácter filosófico que consideramos consistentes y, por cierto, aplicables a una problematización sobre la construcción de la noción de indio en los Andes coloniales. Nos referimos especialmente a los conceptos de «mestizaje cultural» $\mathrm{y}$ «códigofagia». De este modo los define Bolívar Echeverría:

El mestizaje cultural ha consistido en una «códigofagia» practicada por el código cultural de los dominadores sobre los restos del código cultural de los dominados. Ha sido un proceso en que el devorador ha debido muchas veces transformarse radicalmente para absorber de manera adecuada la substancia devorada; en el que la identidad de los vencedores ha tenido que jugarse su propia existencia intentando apropiarse de la de los vencidos ${ }^{9}$.

La cita posiciona claramente ambas nociones en tanto que un devorar constante entre códigos culturales. Es ahí donde, de forma codigofágica, se construye un tipo de subjetividad culturalmente mestiza, limítrofe, fronteriza, en movimiento. Hablamos de una subjetividad que no encaja con el indio «en su sentido estricto» (etnocentrado), sino que apropia, agencia y re-direcciona la noción de indio «en sentido amplio». Esto implica plantear nuevamente la fundamental pregunta por la identidad cultural. Frente a ello insiste Echeverría:

Si la identidad cultural deja de ser concebida como una sustancia y es vista más bien como un «estado de código» - como una peculiar configuración transitoria de la subcodificación que vuelve usable, «hablable», dicho código-, entonces, esa «identidad» puede mostrarse también como una realidad evanescente, como una entidad histórica que, al mismo tiempo que determina los comportamientos de los sujetos que la usan o «hablan», está siendo hecha, transformada, modificada por ellos ${ }^{10}$.

En consecuencia, la construcción de la noción de indio como «estado de código» compone una subjetividad «evanescente». El indio como identidad cultural (código cultural) se forja en sus posibilidades para devorar y ser devorado. En este nivel de análisis, comprendemos que el abandono de una perspectiva sustancialista (en favor de una lectura semiótica) aleja a Echeverría del esencialismo culturalista latinoamericano. Luego, la «realidad evanescente» es parte de la transformación bajo la cual la noción de indio está siendo constantemente re-construida en tanto código cultural en la medida en que lo «usan y hablan». 
Ahora bien, es prudente reconocer que no son equivalentes todas aquellas subjetividades nombradas como indios. Queremos distinguir brevemente un particular tipo de construcción discursiva dentro de lo indio, a saber, sus élites, precisamente porque son éstas quienes «usan y hablan» o bien interactúan con el código cultural europeo. En esta perspectiva, destacamos el análisis de los espacios y los modos de enseñanza-aprendizaje del español -en términos de la transferencia de conocimientos y saberes - entre los cuales circulan los indios de élite (caciques-kurakas) en el área andina colonial ${ }^{11}$. Retomamos también las lecturas en las cuales este tipo de subjetividades han sido identificadas como ladinas ${ }^{12}$, como zonas de contacto $^{13}$, o bien como passeurs ${ }^{14}$. Estas teorizaciones colaboran en la comprensión de los mecanismos de enunciación en los cuales algunos indios de élite procuran comunicar y posicionar sus pareceres escribiendo sobre sí y sobre su historicidad.

Sobre este asunto, es necesario sumar un elemento fundamental para el análisis relativo al mundo andino colonial, a saber, la relación entre la oralidad y la escritura comprendida dentro un proceso de apropiación cultural. Nos referimos a una reflexión encaminada a cuestionar los límites de los modos civilizatorios occidentales y, con ello, la fricción entre la oralidad y la escritura como fenómeno cultural que afecta directamente al mundo andino colonial. En este sentido, la escritura como modo civilizatorio dominante involucra directamente al «mundo de la vida» del indio en los Andes coloniales, demostrando cómo es posible sobrellevar e instrumentalizar la labor escritural en favor de su propia reconstrucción histórica e identitaria. Sobre ello indica Frank Salomon:

Historically, peoples who spoke Quechua and Aymara (like other Native South Americans) have long been described as eternal outsiders to the world of letters. Indeed some authors have stereotyped them as «oral» cultures, and assigned to them a role as tragic Rousseauian resisters against alphabetic regimentation. But this is mistaken. The more one reads on the lesser-known archives of the countryside, the more one realizes that much of what we know as Andean culture has grown in and through literacy. If this damages the appeal of the Andean as a «nonWestern» culture, so much better. It brings us toward a more realistic encounter with peoples of highland South America, in all their cultural distinctiveness, as actors within the creation of modernity ${ }^{15}$.

La cita evidencia un axioma fundamental que permite comprender la tensión entre la oralidad y la escritura acontecida en los Andes desde tiempos coloniales como un golpe a la modernidad occidental. Destacamos el cuestionamiento sobre la comprensión del mundo andino como un mundo no-occidental, precisamente porque la contraposición entre lo oral e iletrado y el sentido civilizatorio de la escritura contribuyen al análisis crítico de los mecanismos de enunciación en los cuales

\footnotetext{
11. Alaperrine-Bouyer, 2007.

12. Adorno, 1992; Bernand, 2001.

13. Pratt, 1991.

14. O'Phelan y Salazar, 2005.

15. Salomon y Niño-Murcia, 2001, p. 1
} 
el indio ha encontrado su lugar en Occidente a través de la creación escritural de su modernidad.

Ejemplo de este proceso creativo es la obra del Inca Garcilaso, porque se nos presenta entre el traspaso y la consolidación de horizontes alternativos de pregunta y comprensión en los Andes coloniales. El Inca Garcilaso muestra una historicidad en proyección que re-ubica diferentes modos de construcción discursiva a través de una narración histórico-literaria, a través de una «crónica mestiza» ${ }^{16}$ que se configura de forma "polifónica o coral» ${ }^{17}$. En su escritura es donde se vuelve axis mundi en virtud de su posición «policultural y polilógica» ${ }^{18}$, especialmente debido a los altos grados de movilidad y co-pertenencia en sus construcciones discursivas. No obstante, referir al Inca Garcilaso implica dejarlo hablar, dejarlo mostrar aquellas indicaciones, huellas y rastros, que pueden re-direccionar los múltiples sentidos de las nociones de indio, inca y mestizo. Dejarlo hablar implica, en este punto, rodear concéntricamente este texto cultural y destacar algunas claves hermenéuticas que interoperan en sus construcciones discursivas y que persiguen, ulteriormente, un pensamiento que retoma - conjuntamente- las nociones de indio, de inca y de mestizo como identidades culturales evanescentes y en movimiento.

\section{SOBRE LAS NOCIONES DE INDIO, INCA Y MESTIZO EN LOS COMENTARIOS REALES DE LOS INCAS}

A fin de llevar a cabo una aproximación filosófico-política sobre las nociones de indio, inca y mestizo en la producción histórico-literaria del Inca Garcilaso, centraremos nuestro esfuerzo en un breve análisis sobre la «Primera parte de los Comentarios reales de los Incas» (1609). Ahí buscaremos seguir las huellas de algunos elementos interpretativos útiles en la problematización sobre su noción de indio, su relación con el inca y, ciertamente, su vectorización en el mestizo. Pues bien, en el pensamiento del Inca Garcilaso las nociones de indio e inca son dúctiles y nómadas. Muy diferente es ser un inca en los Andes y ser un indio en Europa. La complejidad de este acercamiento se define en la polivalencia del indio al momento de definir al inca, que requiere de una explicación etnocentrada y que difiere -en muchos aspectos - de la noción europea de indio. ¿El indio es un inca? ¿El inca es un indio? Ambas preguntas posicionan las complejidades del discurso garcilasista. En sus Comentarios no hay lugar para reflexiones taxativas, por el contrario, es un espacio abierto para el cuestionamiento sobre los límites del indio y del inca en el horizonte de expectativa polisémico que ambas nociones acarrean.

En los Comentarios se habla del indio y del inca de maneras disímiles y convergentes. Respecto del indio, el Inca Garcilaso sostiene una definición ad hominem: «Para atajar esta corrupción me sea lícito, pues soy indio, que en esta historia yo escriba como indio con las mismas letras que aquellas dicciones se deben escribir» ${ }^{19}$.

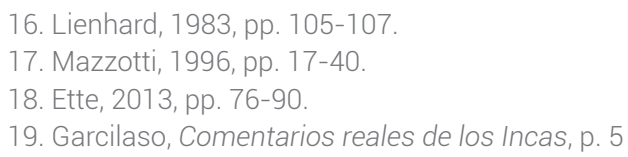


Por una parte, reconoce la «conciencia idiomática» como fundamento lingüístico y simbólico de autoridad para su discurso ${ }^{20}$, y por otra, la polisemia del concepto de indio en términos de su construcción identitaria. Finalmente, podemos sostener que toda referencia al indio cumple con un ejercicio de desmonte y reubicación de niveles de interpretación; como hemos indicado, el indio es un término evanescen$t^{21}$. Sin embargo, hay un insoslayable argumento teológico-político que entrega historicidad a la noción de indio, a saber, los indios son seres humanos creados por el Dios cristiano. El Inca Garcilaso desarrolla un recurso retórico para explicar e incluir este tipo de historicidad o temporalidad en el continuum de la historia cristiana (occidental). Para ello recurre a las «Edades del Hombre» siguiendo el modelo agustiniano compuesto por tres momentos ${ }^{22}$. La «Primera Edad» se identifica con la bestialidad y la carencia, con la behetría y el politeísmo. La «Segunda Edad» refiere al inca y se distingue estratégicamente como por su impacto civilizatorio que transforma la bestialidad del hombre andino antiguo. Bien se recalca, el inca es quien trae orden y policía, puesto que es runa: «hombre de entendimiento y razón» y no Ilama: «bestia» ${ }^{23}$. Finalmente, la «Tercera Edad» es el momento de la «gloria», de la salvación en virtud de la llegada del cristianismo como verdad revelada a «estas tierras». No exento de dificultad, el ejercicio de pensar al indio desde su condición previa a la evangelización se posiciona como un asunto inexorable. Entonces, es preciso determinar qué rol juega el inca dentro de este tipo de conceptualizaciones, especialmente en torno a su relación con aquel indio que no es runa. Sobre ello, sostiene el Inca Garcilaso:

El nombre Inca en el príncipe quiere decir «señor» O «rey» O «emperador». Y en los demás quiere decir «señor». Y para interpretarlo en toda su significación, quiere decir «hombre de la sangre real». Que a los curacas, por grandes señores que fuesen, no les llaman Inca. Palla quiere decir «mujer de la sangre real». Y para distinguir al rey de los demás Incas le Ilaman Zapa Inca, que quiere decir «Solo señor», de la manera que los suyos llaman al Turco «Gran señor» ${ }^{24}$.

La cita distingue al Inca de los curacas (señores locales) en un esfuerzo por aclarar jerarquías y orígenes. En estos detalles el Inca Garcilaso no escatima su etnocentrismo. En su construcción discursiva destacamos un «orden jerárquico progresivo» de alcance «cósmico y universal», que se acerca en sus reflexiones a León Hebreo y la cábala (como paradigma epistémico), y que presenta al «entendimiento» como agente reflexivo, racional y divino presente en todo ser humano ${ }^{25}$. Pues bien, en el discurso garcilasista, y de forma vehemente en los Comentarios, el inca es un civilizador conforme a sus «preceptos», «leyes»y «buen gobierno» ${ }^{26}$. En este sentido, el inca no es cualquier indio, puesto que entrega al indio un acce-

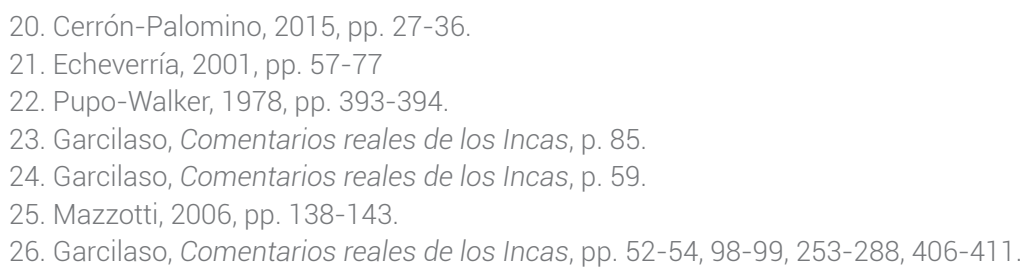


so al logos, a la lumen naturale, demostrado por su «entendimiento» y su vida en policía. El indio que es inca dominó a otros, educó a otros. Por ello los avatares de los incas y las consecuentes indicaciones sobre su historia y su construcción social y política son determinantes para la continuidad narrativa de los Comentarios. Aquí los modos de relación entre el indio y el inca responden, a criterios articulados conforme a la polivalencia de ambas nociones, donde cada una funciona como un concepto filosófico-político en construcción. Entonces, es necesario reconocer que en los Comentarios las trayectorias entre el indio y el inca son ambiguas e interrelacionadas. En rigor, la virtud civilizatoria del inca es extensible, y el indio es un concepto dúctil y adaptable. Ambas nociones se presentan entre dos tradiciones discursivas: la europea y la incaica (andina), y consolidan tensiones y explicaciones que, ulteriormente, aclaran el conflicto del «sujeto de escritura» ${ }^{27}$ con un problema mayor, a saber, la construcción de su identidad cultural como mestizo.

Es prudente referir al mestizo desde una dimensión multidireccional y fragmentaria relacionada de manera especial con el indio y el inca. Seguiremos un enfoque que busca atender las resonancias de un discurso heterogéneo. Retomamos esta indicación como nuestro axioma interpretativo: «Garcilaso habla a veces como servidor fiel de su Majestad, a veces como mestizo doblemente noble, a veces simplemente como mestizo, a veces como inca y a veces como indio» ${ }^{28}$. En el libro IX se introducen varios capítulos relativos a aquellos nuevos elementos llegados o bien generados a partir del encuentro entre los mundos, donde relevamos lo referido sobre los caballos, vacas y bueyes, para proseguir con otros seres vivos y productos agropecuarios ${ }^{29}$. Destacamos ahí el capítulo XXXI, titulado: «Nombres nuevos para nombrar diversas generaciones», donde se explican aquellas nuevas mezclas, tales como el mestizo, como un efecto del nuevo escenario histórico acontecido a escala global desde el kairós de 1492. En esta argumentación se entrega autoridad al mestizo, por su condición y calidad, dentro de un escenario mayor y complejo: las Indias. Sobre ello, el Inca Garcilaso inicia su argumentación indicando que:

Lo mejor de lo que ha pasado a Indias se nos olvidaba, que son los españoles y los negros que desde entonces acá han llevado por esclavos, para servirse de ellos, que tampoco los había antes en aquella mi tierra.

De estas dos naciones se han hecho allá otras, mezcladas de todas maneras. Y para diferenciarlas les llaman por diversos nombres para entenderse por ellos ${ }^{30}$.

Se asume aquí una posición favorable referida a la introducción de españoles y negros, y a la consecuente producción y denominación de las mezclas, de lo que ha llegado desde el Viejo Mundo y que podemos comprender como una afirmación identitaria para el Nuevo Mundo. A continuación sostiene su canónica definición sobre el mestizo:

\footnotetext{
27. Mazzotti, 1996, pp. 328-333.

28. Cornejo Polar, 2013, p. 78.

29. Garcilaso, Comentarios reales de los Incas, pp. 598-626.

30. Garcilaso, Comentarios reales de los Incas, p. 627.
} 
A los hijos de español y de india -o de indio y española- nos llaman mestizos, por decir que somos mezclados de ambas naciones.

Fue impuesto por los primeros españoles que tuvieron hijos en Indias. Y por ser nombre impuesto por nuestros padres y por su significación me lo llamo yo a boca llena y me honro con él ${ }^{31}$.

La declaración de principios es clara, y son claras también las dimensiones fenotípicas y políticas que configuran al mestizo. A partir de la cita es posible llevar a cabo un cuestionamiento sobre el lugar del indio y el español en relación con el mestizo. El mestizo tiene una doble configuración (indiana/andina e hispana/occidental) que determina su existencia como original y regenerativa. En este sentido, el indio es un componente constitutivo pero incompleto, que incorpora a lo hispano (europeo) como su inexorable complemento. El mestizo, entonces, es el nombre impuesto para el resultado afirmativo de la adecuación entre dos mundos. Aquí el mestizo es una subjetividad en conflicto que se vectoriza desde un desdoblamiento discursivo entre lo indio y lo hispano. En este desdoblamiento el Inca Garcilaso localiza el lugar originario del indio a través de la figura del inca. En consecuencia, y puesto que no cualquier indio es runa, el indio que es inca toma relevancia, principalmente debido a su contenido filosófico-político y su autoridad simbólica basados en el dominio civilizatorio ejercido sobre los otros indios.

En suma, es posible sostener que en los Comentarios se articula una relación «codigofágica» ${ }^{32}$ entre lo indio, lo inca y lo mestizo, y que nos permite delinear sus propuestas relativas al carácter filosófico-político presente en su obra. Aquí filosofía política se construye en las contradicciones de una subjetividad polivalente, vacilante y ambigua; una subjetividad agónica que no se lleva a cabo en términos de una armonía ideal sino «en convivencia forzosa, dolorosa, difícil y traumática» ${ }^{33}$. En medio de esta convivencia forzosa el Inca Garcilaso es creador un discurso identitario móvil y dúctil. Hemos señalado cómo estas tres nociones: indio, inca y mestizo, desde la polisemia y multidireccionalidad, funcionan en un ejercicio crítico que se construye entre subjetividades y discursos, y donde la profundidad de su reflexión filosófico-política se presenta a través del reconocimiento de un proyecto civilizatorio moderno bifurcado ${ }^{34}$. En los Comentarios estas tres nociones no claudican en el esfuerzo por articular un proyecto filosófico-político, por reafirmar un proyecto cultural e identitario, en la reconstrucción y transformación de un mundo moderno concebido esta vez desde la co-pertenencia entre lo indiano, lo incaico y lo mestizo.

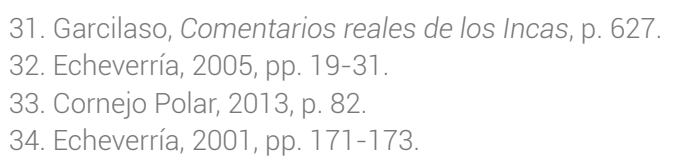




\section{BIBLIOGRAFÍA}

Acevedo, Jorge, «En torno a la interpretación heideggeriana del principio de razón suficiente», Revista Diálogo, 81, 2003, pp. 15-34.

Adorno, Rolena, «El indio ladino en el Perú colonial» en De palabra y obra en el Nuevo Mundo. Imágenes interétnicas, ed. Miguel León-Portilla Manuel Gutiérrez Estévez, Gary H. Gossen y Jorge J. Klor de Alva, México, Siglo Veintiuno, 1992, pp. 369-395.

Alaperrine-Bouyer, Monique, La educación de las élites indígenas en el Perú colonial, Lima, Instituto Francés de Estudios Andinos/Instituto Riva Agüero, 2007.

Aristóteles, La Política, Madrid, Gredos, 1988.

Bernand, Carmen, «Mestizos, mulatos y ladinos en Hispanoamérica: un enfoque antropológico de un proceso histórico», en Motivos de la antropología americanista. Indagaciones en la diferencia, coord. Miguel León Portilla, México, Fondo de Cultura Económica, 2001, pp. 105-131.

Bernand, Carmen y Serge Gruzinski (ed.), Historia del Nuevo Mundo. Tomo I. Del Descubrimiento a la Conquista. La experiencia europea, 1492-1550, México, Fondo de Cultura Económica, 1996.

Cerrón-Palomino, Rodolfo, Tras la huellas del Inca Garcilaso. El lenguaje como hermenéutica en la comprensión del pasado, Boston, Latinoamericana, 2013.

Cornejo Polar, Antonio, Escribir en el aire. Ensayo sobre la heterogeneidad sociocultural en las literaturas andinas, Lima, Latinoamericana, 2011.

Echeverría, Bolívar, Las ilusiones de la modernidad, Quito, Tramasocial, 2001.

Echeverría, Bolívar, La modernidad de lo barroco, México, Era, 2005.

Ette, Ottmar, Viellogische Philologie. Die Literaturen der Welt und das Beispiel einer Transarealen Peruanischen Literatur, Berlin, Kadmos, 2013.

Ferrater Mora, José, Diccionario de filosofía, Barcelona, Ariel, 1994.

Garcilaso de la Vega, Inca, Comentarios reales de los Incas, México, Fondo de Cultura Económica, 2005 [1609].

Lienhard, Martin, «La crónica mestiza en México y el Perú hasta 1620: Apuntes para su estudio histórico-literario», Revista de Crítica Literaria Latinoamericana, 17, 1983, pp. 105-115.

Martínez, José Luis, «Construyendo mundos: el nacimiento de los indios en los Andes del siglo XVI», en Del Nuevo al Viejo Mundo: Mentalidades y Representaciones desde América, ed. Alejandra Araya, Azún Candina y Celia Cussen, Santiago, Fondo de Publicaciones Americanistas, 2007, pp. 23-34.

Mazzotti, José Antonio, Coros mestizos del Inca Garcilaso. Resonancias andinas, Lima, Fondo de Cultura Económica, 1996. 
Mazzotti, José Antonio, «Otros motivos para la Traduzion: el Inca Garcilaso, los diálogos de amor y la tradición cabalística», en Franqueando fronteras. Garcilaso de la Vega y la Florida del Inca, ed. Raquel Chang-Rodríguez, Lima, Fondo Editorial Pontificia Universidad Católica del Perú, 2006, pp. 131-148.

O’Phelan, Scarlet y Carmen Salazar (ed.), Passeurs, mediadores culturales y agentes de la primera globalización en el mundo ibérico, siglos XVI-XIX, Lima, Instituto Francés de Estudios Andinos, 2005.

Pratt, Mary Louise, «Arts of the Contact Zone», Profession, 91, 1991, pp. 33-40.

Pupo-Walker, Enrique, «Los Comentarios reales y la historicidad de lo imaginario», Iberoamericana, 44, 1978, pp. 385-407.

Salomon, Frank y Mercedes Niño-Murcia, The Lettered Mountain: A Peruvian Village's Way with Writing, Durham, Duke University Press, 2001. 
